\title{
The Hidden Potential of Luminescent Solar Concentrators
}

\author{
Ioannis Papakonstantinou*, Mark Portnoi*, and Michael G. Debije*
}

Prof. I. Papakonstantinou, M. Portnoi

Photonic Innovations Lab, Department of Electronic and Electrical Engineering, University College London, London, WC1E 7JE, UK

*E-mail: i.papakonstantinou@ucl.ac.uk, mark.portnoi.12@ucl.ac.uk

\section{Debije}

Stimuli-responsive Functional Materials and Devices, Chemical Engineering \& Chemistry, Eindhoven University of Technology, $5600 \mathrm{MB}$, Eindhoven, the Netherlands

*E-mail: m.g.debije@tue.nl

Keywords: luminescent solar concentrator, static, dynamic, alternative applications review

\begin{abstract}
The luminescent solar concentrator (LSC), originally introduced almost four decades ago as a potential alternative/complement to silicon solar cells, has since evolved to a versatile photovoltaic (PV) solution with realistic potential for seamless integration into the urban architectural landscape. Yet, a popular perception of the device still persists: the LSC is mostly seen as just a low-efficiency solar panel. This review challenges this outdated notion and argues that the LSC is, to the contrary, a powerful and highly adaptive photonic platform with many more capabilities and potential than only generating electricity from sunlight. The field has seen a rapidly expanding application portfolio over the last few years, with LSCs now considered in various sensing applications, 'smart' windows, chemical reactors, horticulture and even in optical communication and real-time responsive systems. The main goal of this work is to shed light onto this alternative application space and highlight LSC's unique spectral manipulation, light distribution and light concentration properties, and as a result, encourage the participation from a broader range of disciplines into LSC research with the ultimate goal of stimulating the development of novel, LSC inspired technologies.
\end{abstract}




\section{Introduction}

The luminescent solar concentrator, or LSC, is suffering from an identity crisis and typecasting. It is generally presented as a static, monolithic, brightly colored block that absorbs incident solar radiation, re-emits the downshifted light such that a fraction is trapped by total internal reflection (TIR) within the higher refractive index lightguide and directs the trapped light to the edges of the device where the escaping photons are eventually converted into a modest electrical current via attached photovoltaic (PV) cells (see Figure 1). The basic LSC device has been presented in this way for over 40 years, and has been reviewed many times for many journals during this period. ${ }^{[1-12]}$ As a briefest summary: the LSC has been presented in many forms and sizes from a few square centimeters up to $5 \mathrm{~m}^{2}{ }^{[13]}$ using a variety of luminescent species, including organic dyes, inorganic quantum dots and phosphors. ${ }^{[3,11,14,15]}$ Device efficiencies tend to be modest, with values of $7.1 \%{ }^{[16]}$ for a device employing GaAs photovoltaics (PVs) and 4.2\% using silicon PV ${ }^{[17]}$ being among the highest reported. Some other notable examples of conventional LSC design deployments include noise barriers ${ }^{[13,18]}$, $\operatorname{artworks}^{[19,20]}$, greenhouses ${ }^{[21]}$, roofing elements ${ }^{[22]}$, urban furniture ${ }^{[23]}$ and bicycle sheds ${ }^{[23,24]}$, and, in the more transparent state, building windows ${ }^{[25,26]}$, among others.

Despite this portrayal, the LSC is actually an extremely versatile and powerful photonic technology platform, owing to its highly desirable inherent ability to efficiently concentrate incident light, even if diffuse. Conventionally, optical systems are limited by the principle of conservation of étendue, meaning that there is a tradeoff between the acceptance angle $\left(\theta_{a}\right)$ and maximum concentration gain that can be achieved. However, in the presence of a Stokes shift, $\Delta \omega$, étendue needs not to be conserved in the same way: both broad acceptance angles and high concentration gains that grow exponentially with $\Delta \omega$ can be achieved, whilst still adhering to the second law of thermodynamics. ${ }^{[27,28]}$ As an example, the predicted concentration gain for an LSC device operating in the visible region with a $0.25 \mathrm{eV}$ Stokes shift (typical for fluorescent 
dyes used in LSC research) can exceed $10^{4}$, a value which is nearly four orders of magnitude larger than what can be achieved with a device that does not shift frequency. ${ }^{[29]}$ Such extreme calculated (albeit not yet experimentally demonstrated) concentration gains captivated researchers' imagination, who have come up with numerous innovative ways to put LSCs into use, as we will see later in this review. Overall, LSC-based devices can be designed to collect, control and manipulate the spectra and spatial distribution of emitted light, with the exciting possibility for their response to evolve dynamically as a function of time.

What is needed for broad acceptance and dissemination of the LSC technology is a facelift, with the introduction of new approaches, designs and applications to take advantage and accentuate the positive features of the device (light concentration, energy down-conversion and in some cases even up-conversion, color and geometrical diversity, adaptability, mechanical flexibility and property tuneability, amongst other). This is the purpose of this review; we describe some of the alternative applications, roughly distributed among topic areas including horticulture, daylighting, adaptive/switching systems, chemical systems, sensors, biological imaging and detectors for free-space communications and scintillators, distinguishing between static and dynamic systems within the discussions. We also discuss future possibilities for the devices, hoping to spur innovative approaches and applications with an eye on commercial future. 


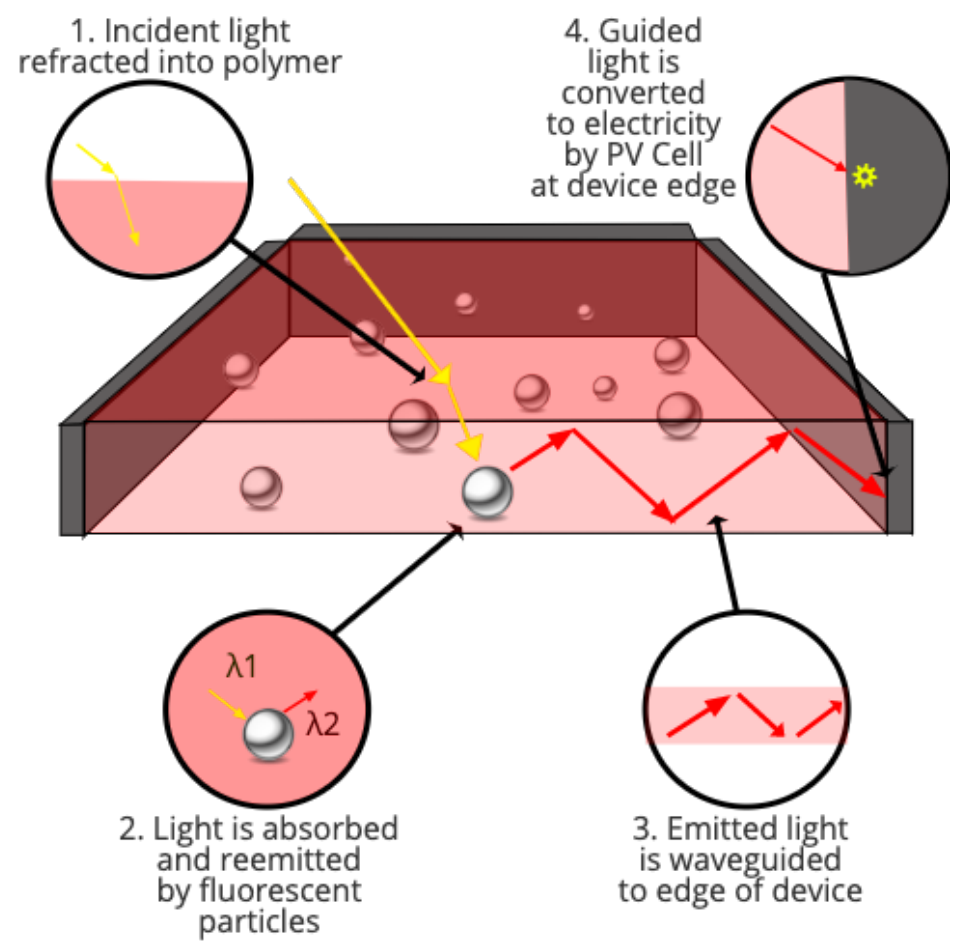

Figure 1. Diagram depicting the principle of operation of a Luminescent Solar Concentrator (LSC) when employed for use in the conventional application of harvesting solar energy.

\section{2. (Primarily) Static Systems}

In this section we detail work done on the more traditional, static LSC. That is, the LSC itself is not designed to change appearance or properties during usage. However, either the form or eventual use of the edge emitted light still differ in these devices from the standard PVbased configurations.

\subsection{Horticulture}

For the controlled, efficient growth of plants with attractive color, taste, and nutritional value in greenhouses or algae raceways, which are shallow ponds divided into a grid containing oval-shaped channels used industrially to cultivate algae, light is the single most critical requirement ${ }^{[30]}$. The light intensity, duration, distribution, and even spectral quality all play 
roles in plant growth, sometimes with different lighting aspects being more critical at different stages of the plant life cycle.

LSCs have been employed in greenhouses as static roofing elements for both color conversion of the incident light for enhancing plant growth as well as for collecting otherwise wasted light for conversion into electricity. ${ }^{[21,31-33]}$ There are examples of large area greenhouses employing bottom-mounted $20 \%$ PV cells covering up to $13.9 \%$ of the panel area (see Figure 2). ${ }^{[21]}$ The use of the panels increased the power emitted by the cells from 9$37 \%$, depending on cell alignment and positioning. The work also suggested stability for at least two decades was possible. ${ }^{[21]}$ In a different embodiment, LSC in the form of long fibers were used to bring light deeper into the plant canopy, where less light is normally incident due to filtering by the upper layers of leaves (Figure 3). ${ }^{[34]}$

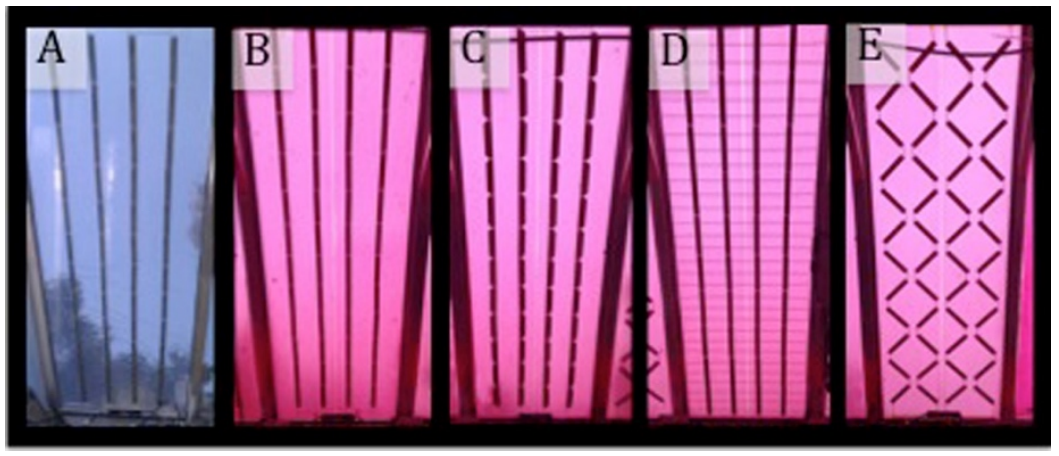

Figure 2. Five different LSC panel designs used for an LSC greenhouse: (A) clear with PV strips; (B) straight PV strips; (C) edge PV cells; (D) polycrystalline PV; and (E) crisscross PV. Reproduced (adapted) with permission. ${ }^{[21]}$ Copyright 2016, AIP publishing. 


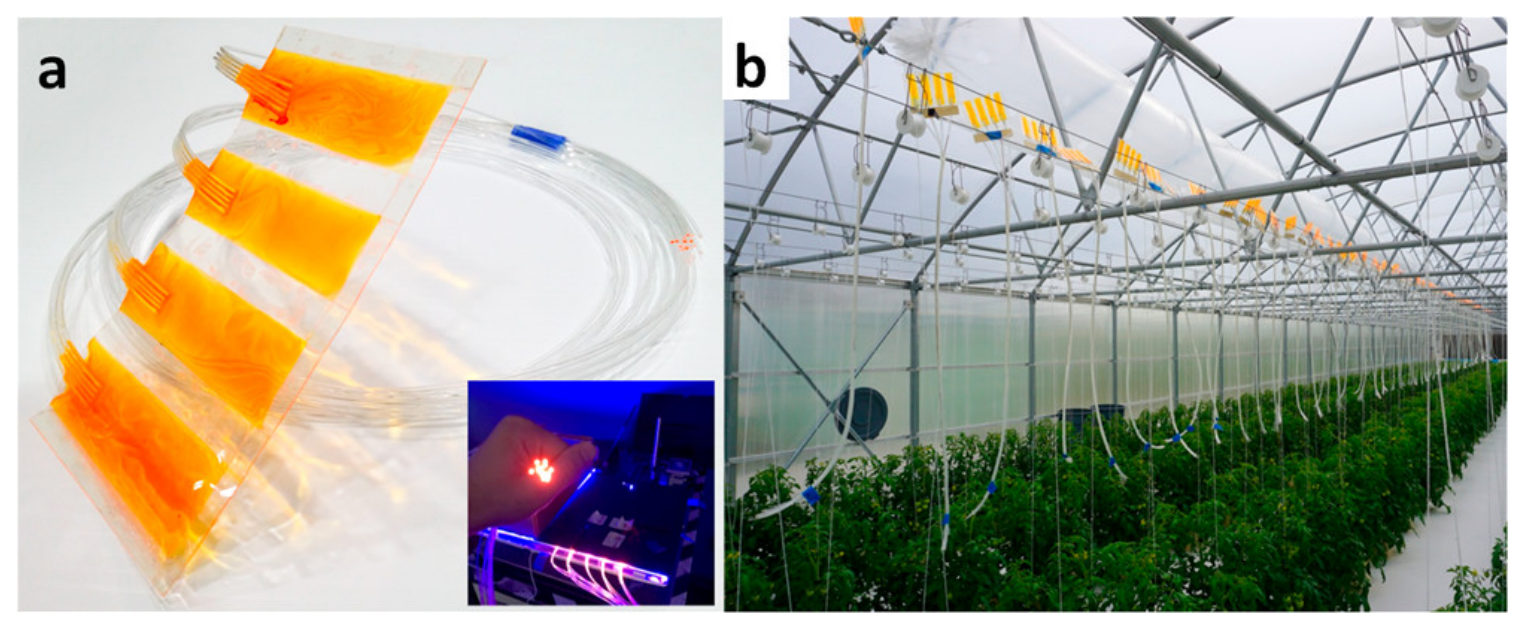

Figure 3. (a) Photographs of a prototype fiber based LSC devices for agricultural deployment. The inset depicts emission during exposure to large-area blue LED lighting. (b) 82 collectors arrayed over a row of tomato plants in a commercial greenhouse. Reproduced (adapted) with permission. ${ }^{[34]}$ Copyright 2019 American Chemical Society.

Another area in which spectral conversion has had a role in agriculture is the growth of algae. ${ }^{[35]}$ There are two main locales for algae growth: large, outdoor raceways and more flask based, interior facilities. LSCs could be very useful in raceway algae production as they work in diffuse light, are relatively inexpensive with no sun tracking needed, with the side effect of generating electricity.

One major challenge for algae raceway production has been the penetration of light into the algal mass. Because of the high density of algae matter within the ponds, it is necessary to churn the organic mass to attempt to allow equal distribution of light throughout the channel. Floating, mushroom shapes LSCs have been suggested for use in raceway algae ponds to allow collection of light, and conversion to a more appropriate color as well as transport deeper into the raceway (see Figure 4). ${ }^{[36]}$ 


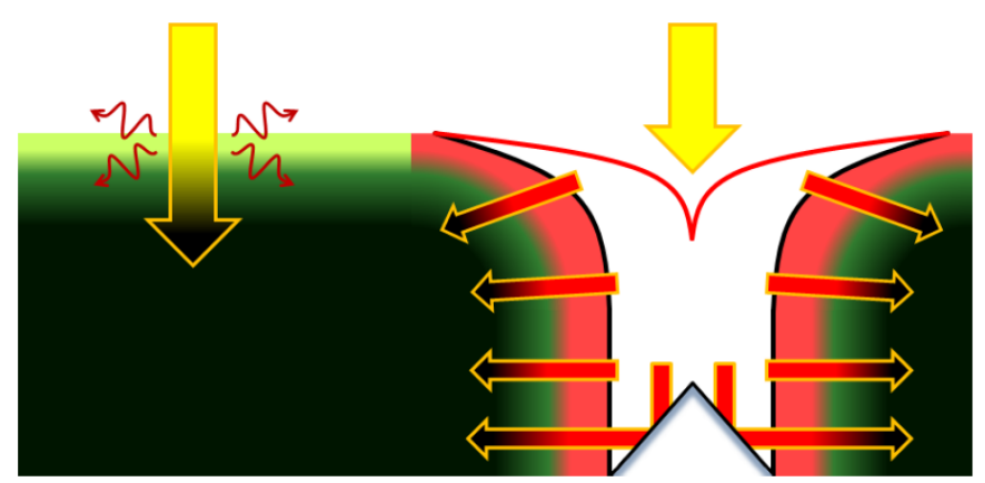

Figure 4. Schematic cross-section of a luminescent solar concentrator diffuser (shown in white), to enhance the penetration of incident light into an algae pond (left). The top of the device, located at the pond surface, is coated with luminescent material (shown in red) and a reflecting cone is fitted at the bottom of the funnel. The device absorbs light at the top surface, spectrally converting it into a more useful wavelength for algae, before diffusing it throughout the depth of the pond. Reproduced (adapted) with permission ${ }^{[36]}$. Copyright 2016 J. Videira.

In flask-based experiments, significant enhancement of algae growth was found by using luminescent materials (Figure 5). ${ }^{[37]}$ Other work has shown similar improvements: by covering growth flasks with luminescent materials, a 36\% increase in biomass productivity of the cyanobacteria Synechococcus sp. was demonstrated. ${ }^{[38]}$ The use of PV / LSC devices in conjunction with algae growth systems demonstrated proper growth conditions for the plants while generating additional power. ${ }^{[39]}$

Two main design challenges have been noted for using LSCs in horticulture: durability and fouling by the organic materials. ${ }^{[17]}$ While the photostability of LSCs is a significant research topic and extended lifetimes have been demonstrated as possible ${ }^{[40,41]}$, there has been little discussion in the literature of lightguide damage from extended use or antifouling solutions (physical or chemical). ${ }^{[42]}$ A recent review of 'smart' materials for use in greenhouse structures describes a number of further potential applications of responsive LSC devices in the horticultural sector. ${ }^{[43]}$ 


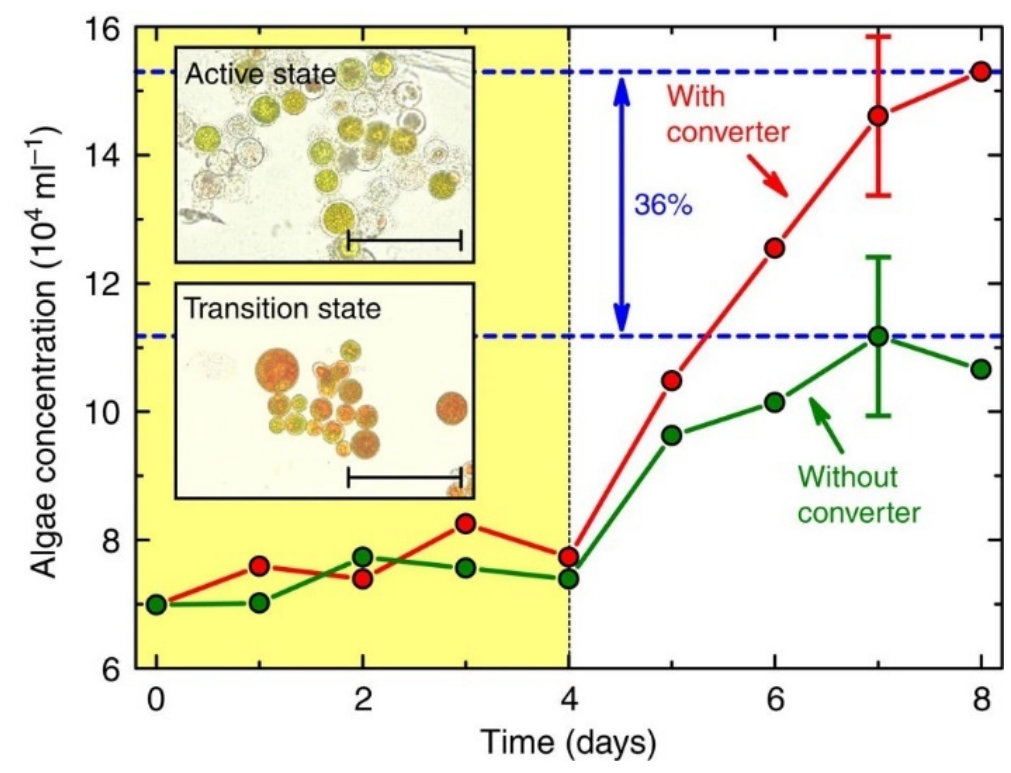

Figure 5. Concentration of algae as a function of time in identical reactor set-ups at room temperature with (red curve) and without (green curve) $\mathrm{Sr}_{0.40} \mathrm{Ca}_{0.59} \mathrm{Eu}_{0.01} \mathrm{~S}$ spectral converter, with insets showing photographs of the algae species $\mathrm{H}$. pluvialis in its active and transition states. The yellow region of the diagram refers to the incubation time. Scale bar, $100 \mathrm{~mm}$, error bars are counting errors of 25,000 cells/ ml. Reprinted (adapted) with permission. ${ }^{[37]}$ Copyright 2013 Nature Publishing Group.

\subsection{Lighting/Displays/Signage}

Researchers have employed a stack of LSC strips to collect sunlight at a rooftop location and, rather than directing it to a PV, generate white light for daylighting purposes after mixing the individual lightguide edge outputs ${ }^{[44-47]}$ or use the light undiffused as an exceptionally bright light source. ${ }^{[48]}$ An advantage of using LSCs over light pipes, for example, is the ability to guide the emission light into optical cabling and so redirect the light around corners and avoid the need for the vertical structures normally found in daylighting pipes, as LSCs do not require direct light to function efficiently. ${ }^{[49]}$

The artistic potential of the LSCs has been exploited by applying the luminophores as a paint on transparent lightguides for the creation of artistic images, ${ }^{[14,50]}$ and using inkjet printing to create intricate designs (see Figure 6). ${ }^{[51]}$ In this latter system, the energy generating aspects of the LSC may be combined with an edge-mounted LED array, so that during the daylight 
hours the device collects solar energy which is stored in a battery, and at night the battery is drained to activate the LEDs, which cause the fluorescent image to light up. ${ }^{[52]}$

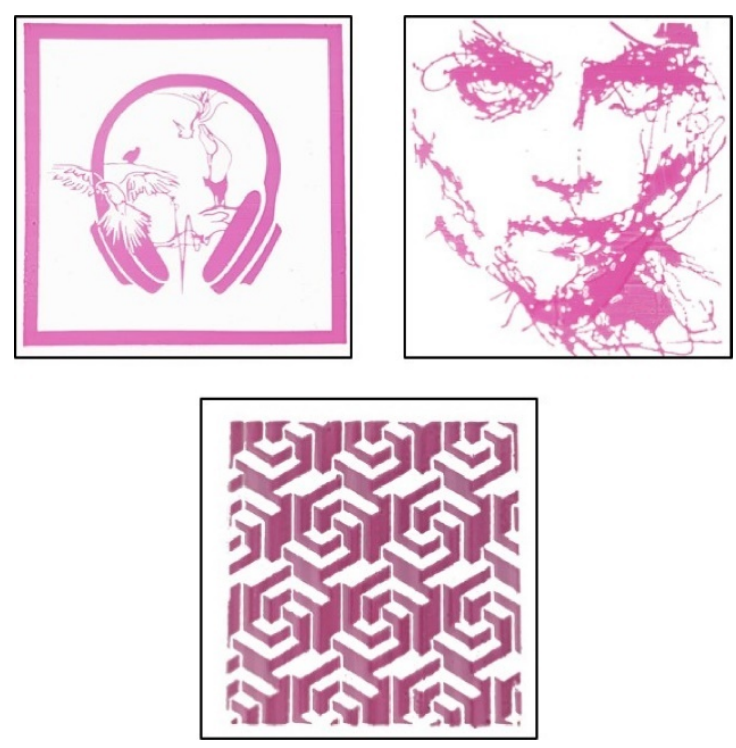

Figure 6. Three LSC samples $100 \times 100 \times 5 \mathrm{~mm}^{3}$ substrates patterned with ink at 15 DPI. Reproduced (adapted) with permission ${ }^{[51]}$ Copyright 2020 Elsevier.

\subsection{Driving Chemical reactions}

Photochemical reactions using sunlight as the energy source for reaction catalysis has been the dream of chemists for more than one hundred years, ${ }^{[53]}$ and has generated interest again after the boom of $1990-2005 .^{[54]}$ One of the challenges for performing efficient photochemistry in sunlight is the relative scarcity of the proper wavelengths in the incident sunlight for absorption by the catalyst, and so progression of the field has been slow. Recently, a luminescent solar concentrator photomicroreactor (LSC-PM) has been developed that shows promise in meeting the goals set out a century ago. ${ }^{[55-57]}$ In these devices, light is collected by the LSC over a large area, and the lightguided emission is directed to the reaction centers, which are solutions flowing through microchannels embedded in the polymer lightguide (Figure 7). The advantages of the LSC device become obvious in this configuration: since the LSC is relatively insensitive to the distribution of the incident light, ${ }^{[49]}$ an LSC-PM device placed in 
sunlight conditions significantly outperformed a standard device which employed no luminescence species. ${ }^{[58,59]}$ A variety of configurations have demonstrated scale-up of the device is quite possible. ${ }^{[60]}$
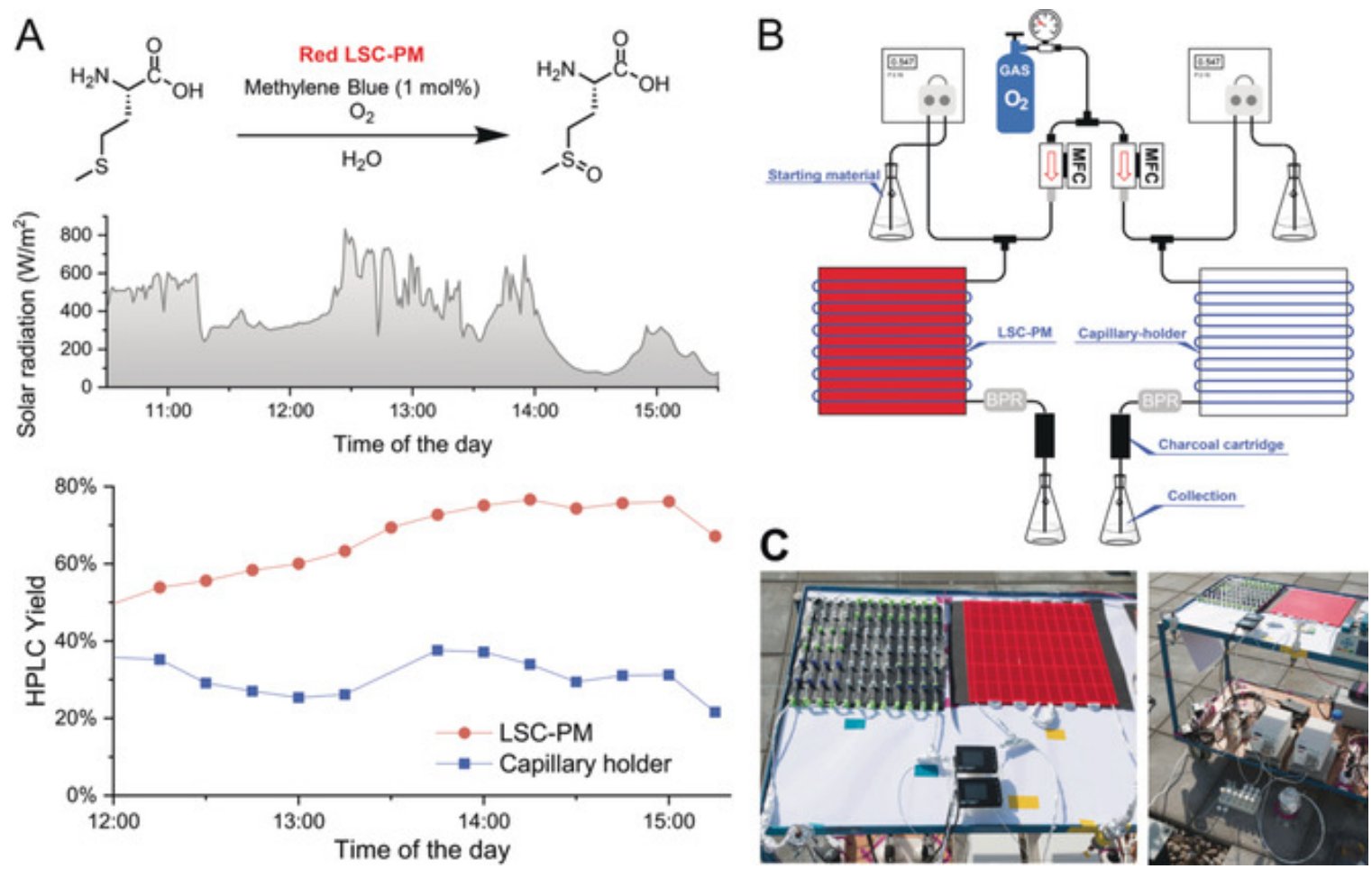

Figure 7. Outdoor experiment for the methylene-blue-catalyzed photooxidation of methionine showing the A) reaction scheme, incident solar irradiation, and product yield over time. B) Flow scheme of the experimental setup, and C) photographs of the experimental setup on site. Reproduced with permission. ${ }^{[59]}$ Copyright 2019 Wiley.

Other photochemistry can be done, such as producing hydrogen via water splitting reactions driven by LSCs (Figure 8). ${ }^{61,62]}$ Initial devices produced a maximum $1.55 \%$ solarto-hydrogen efficiency (STH) at 1 sun AM 1.5 G. ${ }^{[62]}$ Other designs used lenses in conjunction with a dye layer, with direct light focused on a photovoltaic cell and indirect light collected by the dye layer and the emitted light concentrated in the lightguide and directed towards the photoelectrode of the photoelectrochemical reactor. While these results may seem inconsequential considering solar-to-hydrogen (STH) efficiency values up to $30 \%$ have been reported under 1 sun illumination using a triple- junction $P V,{ }^{[63]}$ the costs associated with current systems and difficulties related to deployment in the built environment opens up opportunity for more extensive exploration of the potential of LSCs in this area. 


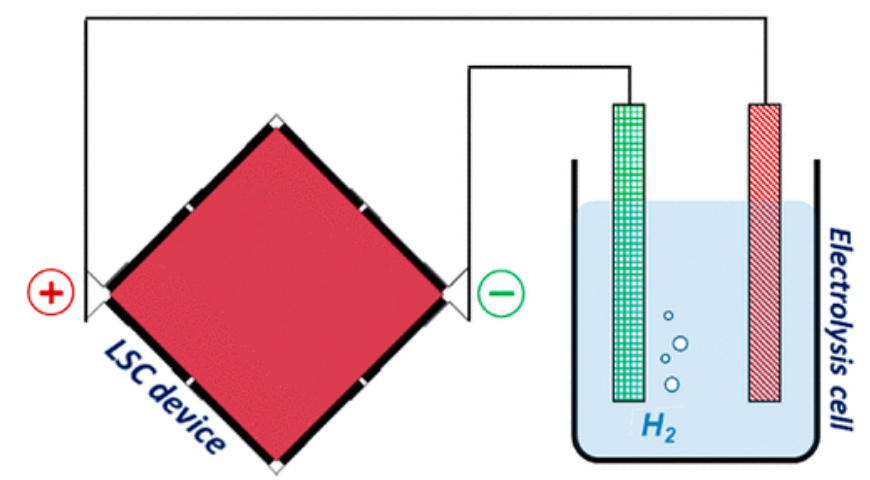

Figure 8. Article abstract image depicting a luminescent solar concentrator (LSC) with multiple c-Si cells connected in series and parallel used as a semitransparent device, generating the potential to conduct water electrolysis without an external bias. Reprinted (adapted) with permission from ${ }^{[62]}$. Copyright 2020 American Chemical Society.

\subsection{Fibers}

Cylindrical LSC devices could allow for greater light concentration than standard rectangular plates. By reducing the cross-sectional area, one can produce fibers with a variety of geometries, including circular, ${ }^{[64-69]}$ square ${ }^{[70]}$, asymmetric (see Figure 9), ${ }^{[71]}$ with a core/cladding construction, ${ }^{[72]}$ or as hollow tubes. ${ }^{[73]}$ Fibers may be produced inexpensively, and at large scales, ${ }^{[67]}$ and can be used individually or in bundles. ${ }^{[67,69,71]}$ Fibers coated with the luminescent species appeared to outperform doped fibers by up to $\sim 30 \%{ }^{[69]}$ As the acceptance angles of the fibers are much larger than regular PV systems, ${ }^{[67]}$ fiber devices are especially effective at collecting indirect light. ${ }^{[69]}$ By incorporating microstructures into a fiber which produce forbidden bandgaps at specific emission angles, fibers with near $100 \%$ containment of emitted light within the core at limited wavelength spread are postulated. ${ }^{[74]}$ More exotic fiber options have included nanometer size electrospun elements incorporating silver nanoparticles for surface plasmonic enhancement of the dye emissions in conjunction with an organic PV. ${ }^{[75]}$ Fiber LSCs have also been suggested for use in medical diagnostics, telecommunications, and agriculture. ${ }^{[34]}$ 
(a)

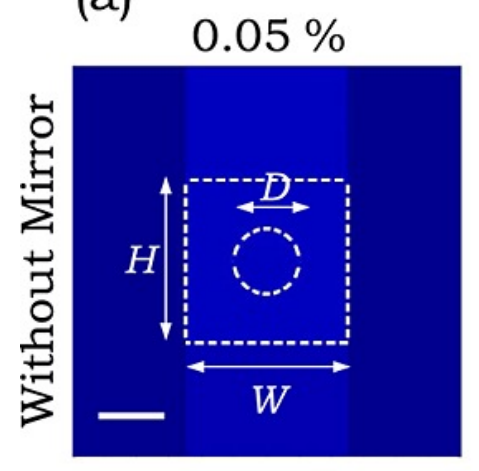

(d)

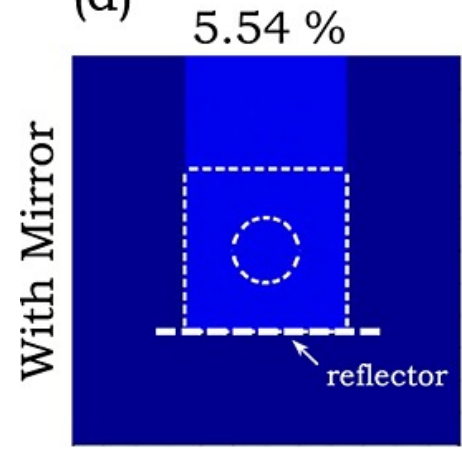

(b)

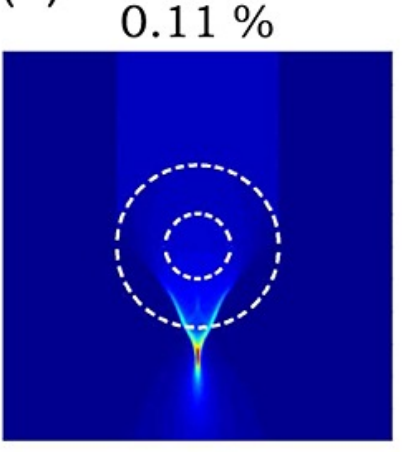

(e)

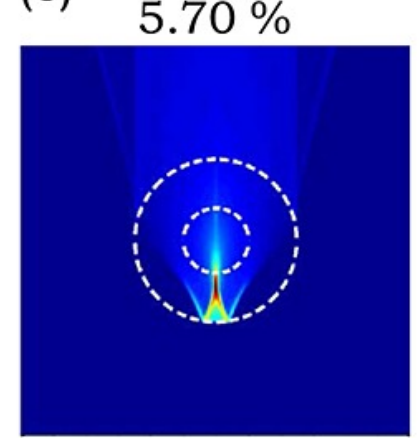

(c)

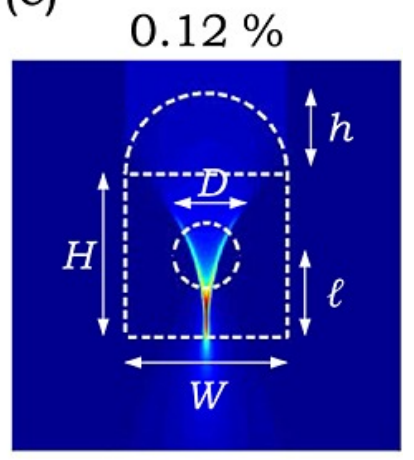

(f)

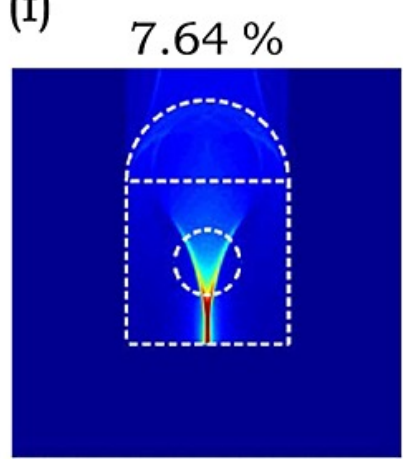

Figure 9. (a)-(c) Ray-tracing simulations of normally incident light in three undoped polymer fiber structures with no back-reflector below the fiber structures. (d)-(f), a flat reflective surface is placed under the fiber (thick dashed horizontal line). The thin dashed white lines highlight the structure, and the dashed circle in the middle of each structure corresponds to the $200 \mu \mathrm{m}$ diameter dye doped. Scale bar is $200 \mu \mathrm{m}$. The number in each panel indicates the fraction of light absorbed due to polymer loss and finite reflectivity of the back mirror. Reproduced (adapted) with permission. ${ }^{[71]}$ Copyright 2013 Wiley.

\subsection{Dark-field imaging}

Recently, one study has taken advantage of the wavelength shifting and direction control of fluorescent doped polymers to create a dark-field imaging technique dubbed 'substrate luminescence-enabled dark-field imaging' (SLED) ${ }^{[76]}$. As shown in Figure 10, the direction of emitted light is carefully controlled using a combination of a nanostructured back reflector and a Bragg mirror. The Stokes shift incurred by the fluorescent materials involved, allows for the separation of illumination beam from image by means of dichroic mirror. This setup was used in the imaging of sub-micrometer features of low refractive-index contrast materials. For example, when imaging $1 \mu \mathrm{m}$ polystyrene colloids, the imaging technique produced a threefold improvement in contrast compared to corresponding bright-field imaging 
techniques. More impressively, when imaging Escherichia Coli (E Coli) samples, the enhancement of the SLED contrast over conventional imaging was a factor of over 20.

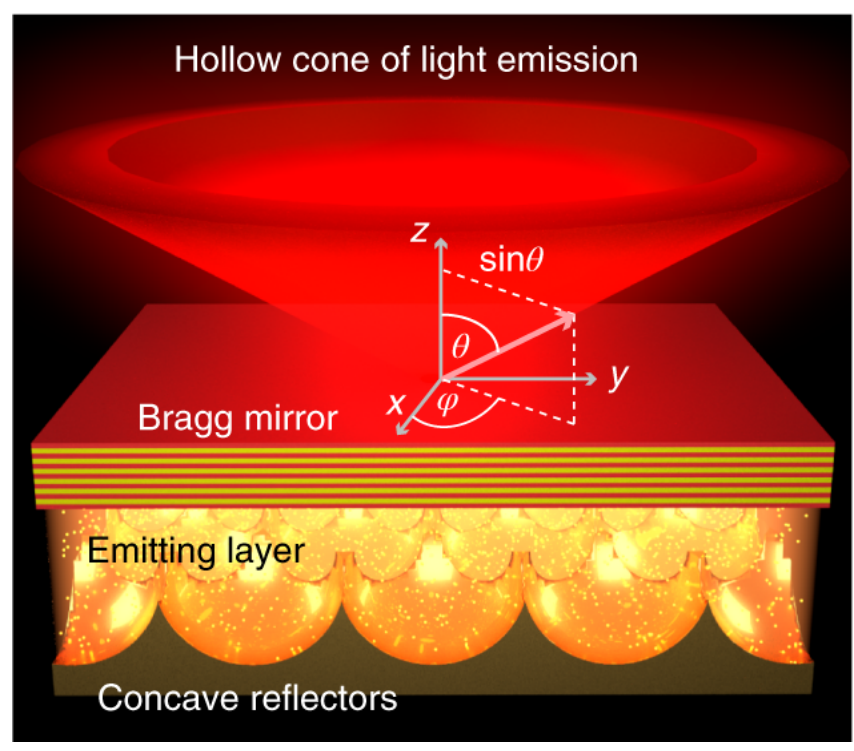

Figure 10. Diagram representing the setup used for control of the direction of emitted light in a dark-field imaging setup. Reproduced with permission. ${ }^{[76]}$ Copyright 2020 Springer Nature Publishing Group.

\subsection{Alternative materials, locations, shapes.}

LSCs have generally been depicted with square or rectangular surface areas, but this need not be so. Triangular ${ }^{[77]}$ and even circular ${ }^{[78]}$ devices have been presented. Likewise, while polymers including polymethacrylate (PMMA) and polycarbonate or glass have been the main materials used for lightguides, alternatives exist, including renewable polyester ${ }^{[79]}$, selfhealing materials ${ }^{[80]}$, and even liquid LSCs have been described ${ }^{[81-83]}$, which could have the advantage of rapid switching of the fluorophore. The employment of flexible materials as host matrixes, such as polydimethylsiloxane (PDMS) ${ }^{[84-86]}$, can open a new range of applications such as boat sails, tents, phone cases and self-powered flexible electronic devices. Device flexibility can also open a gateway towards manufacturing techniques for upscaling such devices, including roll-to-roll processing. Whilst device flexibility can result in additional, curvature induced, losses ${ }^{[85,87]}$, these can be mitigated by using flexible wavelength selective mirrors $^{[88]}$. One could also imagine deploying liquid-based LSCs via the fluid pump systems 
studied for agricultural greenhouses ${ }^{[89]}$ to change crop illumination colors upon demand with the potential to attach PV to the piping. LSCs have also been proposed to be used as thermal conversion systems, using the collected light to heat a flowing liquid. ${ }^{[90-92]}$ While much attention is paid to the luminophores used in LSCs, it must be understood the nature of the lightguide material is similarly critical to the functioning of the LSC-based device. ${ }^{[3,93]}$ For any type of large-scale object, the lightguide must demonstrate negligible absorption of the emission light and be free from extraneous particles or voids which may cause scattering for the device to have any hope of efficient function.

Recently, materials relying on amphiphilic polymer co-networks exhibiting resonance energy transfer between separated fluorophores located in different phases of an intimately mixed film have been produced. The flexible nature of the materials has been suggested for use as clothing. ${ }^{[94]}$

Since the PV cells attached to the edges of LSCs tend to operate cooler than when directly exposed to sunlight, ${ }^{[95]}$ the use of LSCs in space missions has been suggested. ${ }^{[96]}$ However, a significant increase in device efficiency will be necessary before the LSC could be deployed outside our atmosphere. Ambitious designs for LSCs employing up-conversion have been proposed, but the efficiency of up-conversion under normal lighting conditions make this a very challenging prospect. ${ }^{[97-100]}$

\section{Dynamic systems}

In this section we will focus on dynamic systems for which the time of photon arrival is of essence, as opposed to the static systems described in Section 2 for which it is (mostly) not. Time offers an extra dimension that can be leveraged to transmit high-speed information through an LSC. A paramount question for any dynamic system, however, concerns the bandwidth they can support, as this sets the bounds to the rate of information that can be 
transported. Streaming high-resolution (4K) video requires bitrates that exceed $10 \mathrm{Mbps}$, for example, while the theoretical download speed for $5 \mathrm{G}$ networks exceeds 10 Gbps. ${ }^{[101]}$ In its simplest form, an LSC incorporates a single luminophore whose decay characteristics follow an exponential distribution. The average time, $\tau$, it takes for an excited molecule to decay to its ground state corresponds to its fluorescence lifetime and was recently shown to be the sole critical parameter limiting the bandwidth of LSC based receiver systems. ${ }^{[102]}$ This is intuitively satisfying as one would expect that the slower the fluorophore's response time, the less its ability to follow rapidly modulated signals. As a matter of fact, ideal LSCs behave analogously to electrical $R C$-circuits with their bandwidth, $\mathrm{B}$, given by the following equation

$$
B(\mathrm{GHz}) \leq \frac{1}{2 \pi<\tau>(n s)}
$$

where $\langle\tau\rangle$ is the effective fluorescence decay lifetime, which takes into account potential multiexponential decay paths. ${ }^{[88]}$

Typically, the lifetimes of fluorophore used in LSCs are between $1 \mathrm{~ns}$ and $100 \mathrm{~ns}$, ${ }^{[103,104]}$ roughly corresponding to a bandwidth range of 1 - $150 \mathrm{MHz}$ per LSC channel. Such bandwidths are sufficient to unlock opportunities in free-space communication links, lens-less imaging, new type of contactless human-computer interactions, real-time sensors and microscopy, among others, and we will discuss how the LSC can contribute and help advance these often wellestablished areas of research in Sections 3.1-3.5. The final section describes the much simpler but useful concept of responsive 'smart' window elements for use in urban settings.

\subsection{Free space optical communications}

The LSC's ability to concentrate light to small areas from a large field-of-view has recently drawn attention from the optical communications community for use in detection systems. Within visible light communications systems (VLC), data is transmitted via modulated LEDs. LSCs have been employed to collect the diffuse signal and concentrate it to small photodiodes 
on their edge(s). The earliest proposed demonstrations of this, largely focused on conventional LSC geometries (cuboidal and planar), paying particular attention to maximum concentration gain. ${ }^{[105]}$ By using a parabolic geometry, one paper achieved enhanced concentration gains, combining imaging and non-imaging concentration. ${ }^{[106]}$ Next, a multilayer approach was demonstrated with a thin film layer of fluorescent materials sandwiched between two microscope slides. ${ }^{[107]}$ Here, the fluorescent layer is responsible for the absorption of incident light, whilst the majority of the waveguiding occurs within the glass slides. As such, the work boasts a concentration gain of 12 , field-of-view angle of $60^{\circ}$, and a tripling of the data rate compared to the bare photodiode. From there, the field turned to further innovative geometries and configurations. A configuration with a multilayered structure, including a grating and multiple layers of fluorescent material was used to achieve field-of-view angle of $60^{\circ}$ and datarates of 400 Mbps. ${ }^{[108]}$ An even more unorthodox geometry, with fibers arranged in a spherical geometry (pictured in Figure 11), led to almost omnidirectional acceptance and data rates of 2.1 Gbps. ${ }^{[109]}$ More recently, a wavelength division multiplexing (WDM) approach was engaged, by taking advantage of a two-fluorophore system with different absorption spectra to separate data transmitted with differing wavelengths, as shown in Figure 11b. ${ }^{[110]}$ LSCs have also been utilized as diffusers at the transmitter end of a VLC network. ${ }^{[111]}$ 

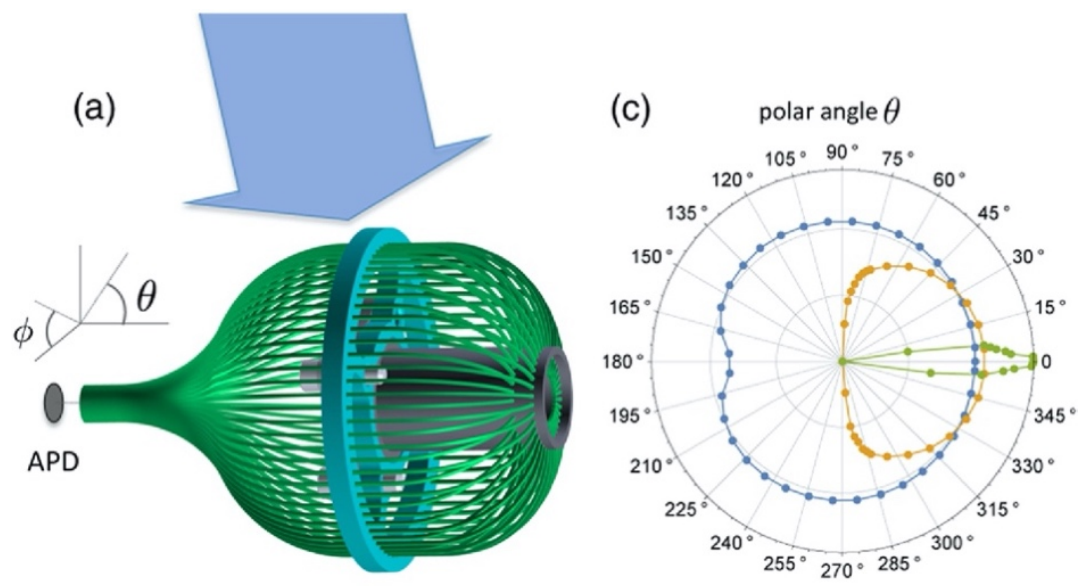

(b)

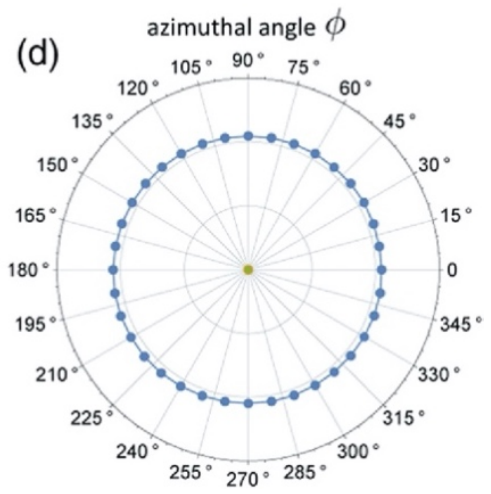

(e)

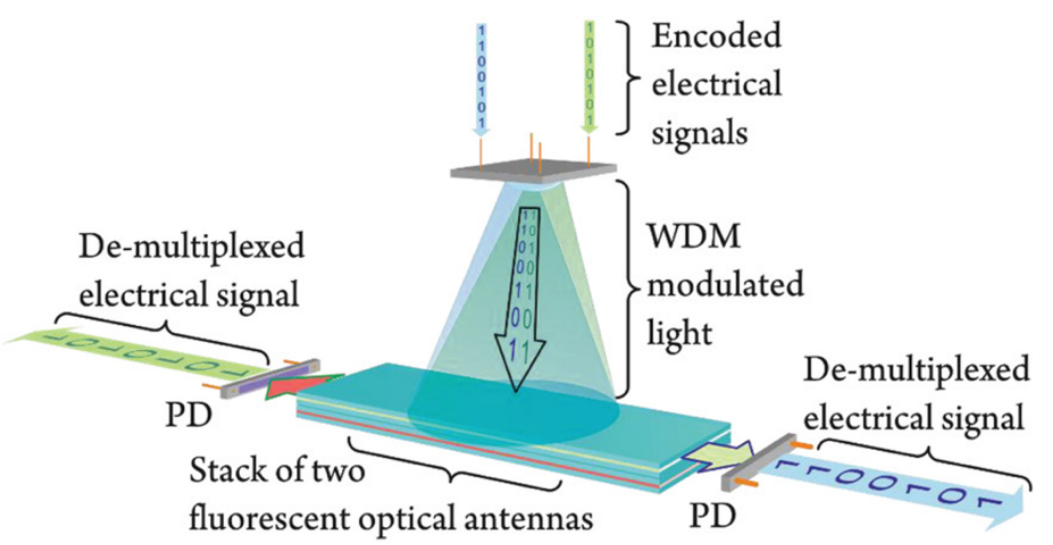

Figure 11. Diagram (a) and photograph (b) of luminescent detector arrangement comprising of a bundle of fibers assembled into a spherical geometry, allowing for near omnidirectional field of view. Polar plots of measured gain for (c) polar and (d) azimuthal angles. Reproduced with permission [109], Copyright 2016 The Optical Society. e) Diagram of two-layer setup used for WDM separation of optical signal. Reproduced with permission. ${ }^{[110]}$ Copyright 2020 Wiley. 


\subsection{X-ray scintillators}

Perovskite nanocrystals have been found to be effective scintillators of X-ray radiation $^{[112,113]}$, and have been encapsulated into polymers in an LSC-like setup and proposed for use as detectors for radiation detection, medical imaging and high energy physics $^{[14]}$, as depicted in Figure 12. In one study, perovskite nanocrystals were responsible for the absorption of X-ray radiation before an energy transfer to a perylene dye, which in turn emits visible light, which can be collected by photodiodes attached to the edge of the LC. The energy transfer between the two fluorescent materials allowed for a reduction in device reabsorption, as well as increased device speed due to the faster fluorescent of the acceptor material. The emission of the dye was in the red spectral region, making it an ideal partner for avalanche photodiodes. The study demonstrated a proof-of-concept detection of both X-ray and Gamma-ray detection, and also demonstrated both high shelf-stability and photostability.

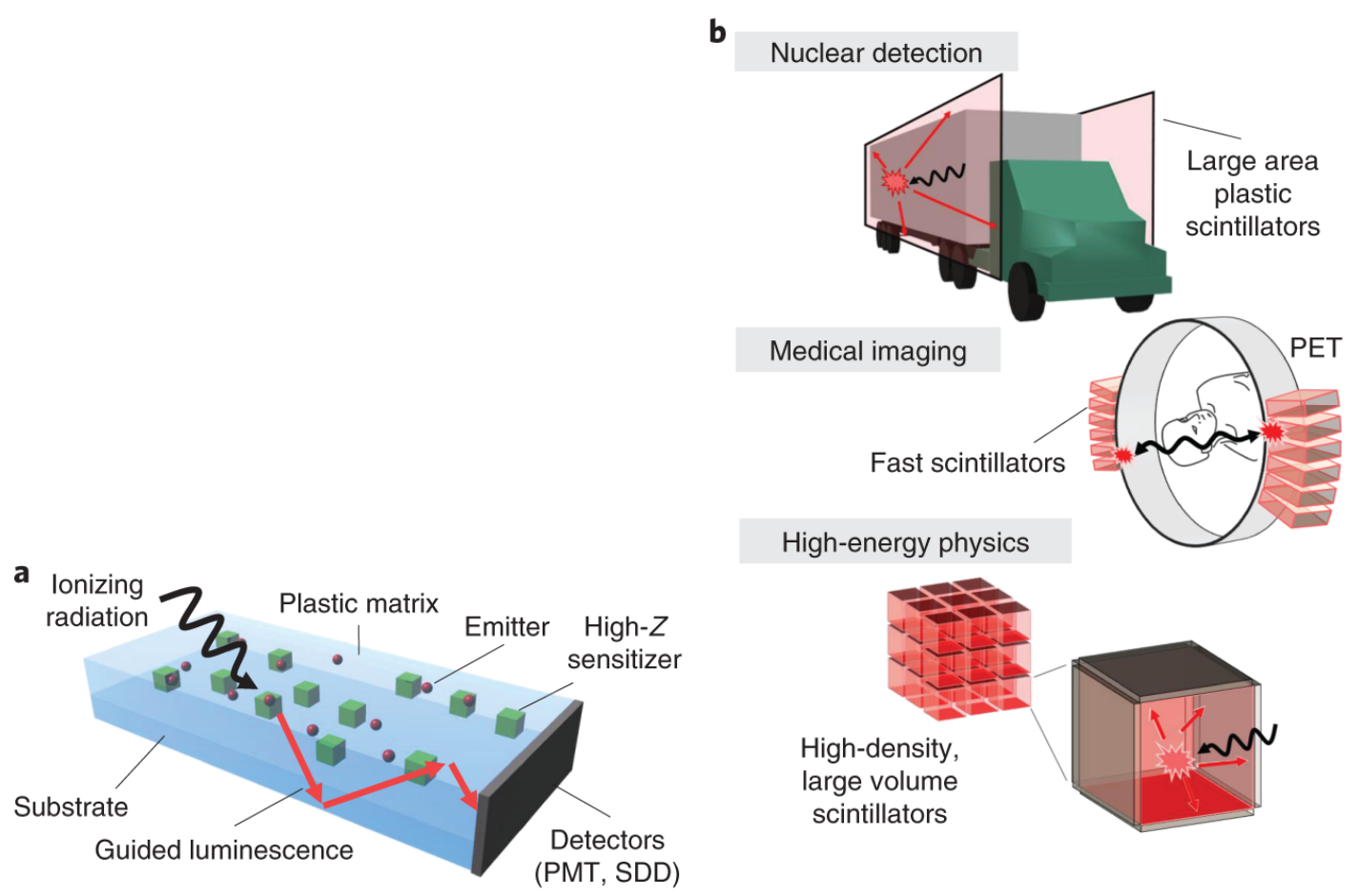

Figure 12. (a) Diagram showing principle of operation of a Perovskite-based scintillator for X-ray detection. (b) Diagram showing applications for scintillator technologies. Figures reproduced with permission. ${ }^{[14]}$ Copyright 2020 Springer Nature Publishing Group. 


\subsection{Imaging/Human-Computer interactions}

An early demonstration of a dynamic LSC system was LumiConSense, a transparent, flexible, lens-less imaging camera ${ }^{[115]}$, shown in Figure 13. The principle of operation of this imaging sensor was based on the different optical path lengths, and thus attenuation, that light experiences when propagating from its origin inside the LSC towards its edges. This implies a direct correlation between the intensity of the light exciting the LSC at a given position and the intensity of the light registered at its edges, which can be recorded by linear arrays of photodiodes or fiber optic arrays. Originally developed for real time reconstruction of $6 x 6$ pixel grayscale images; the system was later extended with application of machine learning to $64 \times 64$ pixel resolution at 8 frames/sec that could be used for 3D hand tracking and gesture recognition. ${ }^{[116]}$ Further developments included multilayer LSCs for RGB reconstruction, ${ }^{[117]}$ multi-focal image reconstruction and depth estimation via tomographic image techniques ${ }^{[118]}$ and sub-millimeter fully flexible image sensors when LSCs were combined with compound microlens arrays. ${ }^{[119]}$

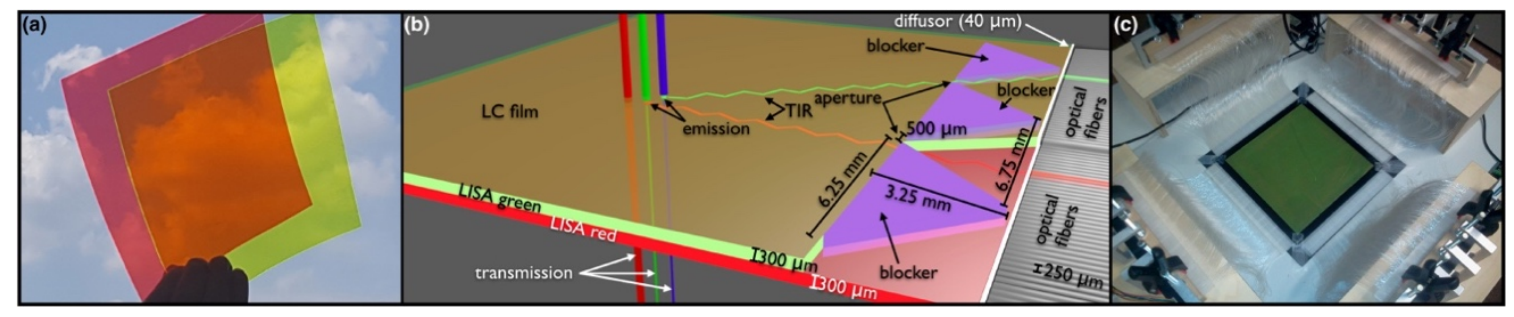

Figure 13. Photograph (a) and Diagram (b) of stacked luminescent concentrators stacked and implemented in a lens-less imaging camera system, as demonstrated in (c). Reproduced with permission ${ }^{[120]}$ Copyright 2015 The Optical Society.

\subsection{Position sensors}

Position sensitive devices find application in guidance systems, robotics, and machine tools, but developing flexible, 2D sensors whilst scaling their sizes up still remains a challenge. LSC systems have been proposed to address this problem in a cost-effective way as early as the mid-1990s by tracking the position of light spots on their surface generated by visible light 
sources. ${ }^{[121]}$ Following that, a video rate $(250 \mathrm{kS} / \mathrm{s})$, large size $(20 \mathrm{~cm} \times 20 \mathrm{~cm})$ position sensor with mean error deviation of $3 \mathrm{~mm}$ was demonstrated by using Bayer Makrofol ${ }^{\circledR}$ RED polycarbonate LC films and 12 surface mount diodes. ${ }^{[122]}$ Replacing the polycarbonate foil with PDMS doped with Pyrromethene 597 enabled the fabrication of a fully flexible sensor, Figure 14a, which could also perform under a $15 \%$ strain with an average deviation of $1.36 \mathrm{~mm}$ for a $4 \mathrm{~cm} \times 4 \mathrm{~cm}$ device. ${ }^{[123]}$ Finally, an alternative approach followed in which the inherent redshifting of trapped light due to reabsorption inside the LSC was used instead of intensity measurements, Figure 14b. ${ }^{[124]}$ One-dimensional position sensors were made with LC fibers constructed with UV-curable resin (Norland, NOA81) and BASF Lumogen F Red 305 dye were also extended to 2D measurements over a $2 \mathrm{~cm} \times 2 \mathrm{~cm}$ area.
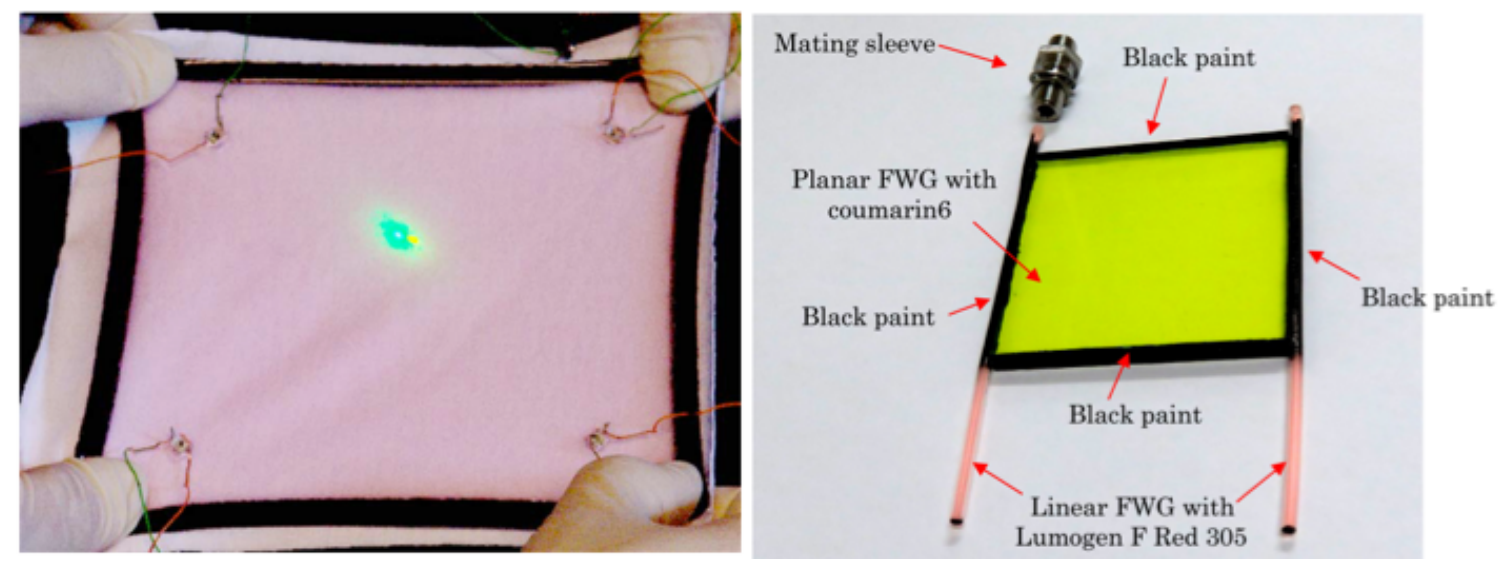

Figure 14. Photograph of the position sensing device fabricated with PDMS which shows strain ability and flexibility (left). Reproduced (adapted) with permission. ${ }^{[123]}$ Copyright 2010 AIP Publishing. Prototype of 2D position sensor using red shifting as the detection mechanism (right). Reproduced (adapted) under the terms of CC BY 4.0 License. ${ }^{[124]}$. Copyright 2019 SPIE.

\subsection{Other sensors}

An LSC fiber-based strain sensor was demonstrated for building and structural monitoring. ${ }^{[92]}$ The core of the fiber was made of Coumarin 540 dye doped PMMA (as donor) and its cladding of Rhodamine 6G dye doped PMMA (as acceptor). The core was excited with a $406 \mathrm{~nm}$ laser that only stimulated the Coumarin 540 dye, and the differences in both emission spectra and near field patterns at the end of the LC fiber for different levels of strain were 
measured. For unstrained fibers, a uniform modal distribution was observed with emission spectrum that matched Coumarin 540 very well. However, as the amount of strain increased, light started leaking from the core into the cladding, resulting in gradual excitation of the acceptor dye. This resulted in a significant change to the measured spectrum and near field pattern, which could then be back correlated to the amount of strain that induced it. An advantage of this method is that severe levels of strain could potentially be identified by simple visual inspection, removing the need for specialized equipment and trained users. The same group replaced the PMMA with PDMS in an attempt to expand the range of strain that could be detected, ${ }^{[125]}$ whereas polarization measurements in a doped fiber was seen as a first step to distinguish the direction of the stress vector. ${ }^{[126]}$

A solvatochromatic dye (Nile red), on the other hand, was used to dope PDMS waveguides. $^{[127]}$ The presence of ethanol shifted the absorption peak of the LSC and a simple intensity measurement at a given wavelength was sufficient to detect the amount of alcohol vapor. Finally, a fluorescent oxygen gas sensor was demonstrated by using a ruthenium complex which exhibits fluorescence quenching under the presence of oxygen. ${ }^{[96]}$

\subsection{Switchable Windows}

The concept for using LSCs in window designs is attractive, and static transparent windows capable of processing UV and IR light have been described and are even on their way to commercialization. ${ }^{[128]}$ However, these static devices must directly compete with thin film PV windows. What has not been readily demonstrated in PV-based fenestration is the ability to switch between transparent and opaque states, something which is possible to do with LSC windows. By using a liquid crystal (LC) as a host, one can reorient the alignment direction of embedded fluorescent dye molecules to create either absorbing or transmissive states by applying an electric field across the window thickness. ${ }^{[129]}$ 
By judicious choice of the host $\mathrm{LC}$, it is possible to generate a third, scattering state in the switching window device, allowing a 'privacy' glass as well as the standard transmissive/absorptive states. ${ }^{[130]}$ One is not even restricted to using electrical switching: windows that change transparency in response to temperature (see Figure 15) ${ }^{[131]}$ and lighting conditions $^{[132]}$ may also be possible. Another interesting design combined the switchable features of a polymer disperse liquid crystal (PDLC) device with that of an LSC to allow generation of scattering and transparent states while simultaneously generating electricity. ${ }^{[133]}$ Finally, by selective illumination of parts of the surface, the window could also display images by scanning a laser beam on it. The displayed image resolution could be modified by 'spreading' the luminescence in the emission layer and the contrast modified by limiting the processing of ambient light. ${ }^{[98]}$
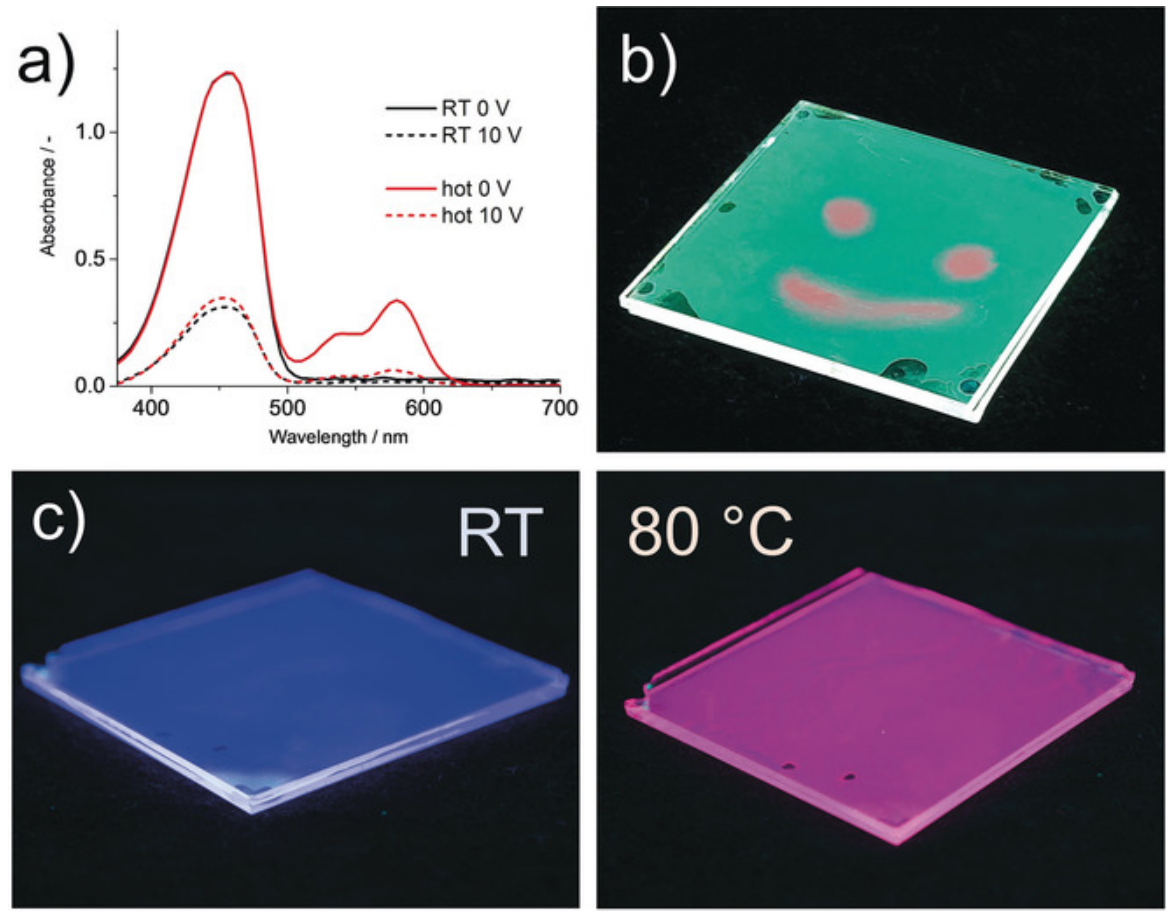

Figure 15. a) Absorbance of the switchable LSC cell containing two dyes demonstrating dual thermal and electrical responsive behavior. b) Heating locally with a soldering iron shows the device can function as a writeable LSC. c) A cell with a different non-crystallizing dye. At RT (left), only the $436 \mathrm{~nm}$ emission is visible; after heating to $80^{\circ} \mathrm{C}$, a pink emission is evident as the first dye dissolves. Reproduced with permission. ${ }^{[131]}$ Copyright 2018 Wiley. 


\section{Outlook and Conclusions}

The LSC was introduced during a period of high oil prices and commensurate high PV panel costs. ${ }^{[1]}$ At that time, the LSC was presented as a potentially affordable source of solar energy which could seamlessly be integrated into buildings, and the prevalent performance metric was given as \$/Watt-peak or similar equivalent. The device was depicted as an alternative to PV panels, which was unwise, for the more limited electrical conversion efficiency could not compete with PV panels once their prices started to fall in the early $21^{\text {st }}$ century. But these early proposals have remained in the collective memory and have had a long-lasting effect, obscuring the true potential of the device and limiting the application space of LSCs to modestly efficient PV cells in the minds of many viewers.

The LSC has a promising application potential in a range of areas; hence, our expectations need be adapted in order to better appreciate the device. Rather than competing with silicon or even perovskite photovoltaics, the LSC could act complimentarily to these devices, with potential for deployment in areas inappropriate for use of traditional PVs with natural integration into the urban architectural landscape.

However, as presented in this review, there are a plethora of potential applications completely removed from the standard 'PV panel on a rooftop' trope. The LSC is a light management device, capable of absorbing incident light, shifting its energy to a narrow bandwidth of emission wavelengths, and redirecting the output so as to decouple emission directions from the incident light directions, while simultaneously achieving high concentration gains. The emission directions can be manipulated ${ }^{[134]}$, and the emission wavelengths tuned to produce light of specific energies to perform specific tasks, such as driving chemical reactions or acting as self-powered position sensors. These authors particularly interested in the possibility of up-conversion-based LSCs, may perhaps use a two-stage approach of first 
collecting mid-range wavelengths which convert to longer wavelengths, concentrating this emission light, and using this light to upconvert to higher energy at reasonable efficiencies without lens systems.

We hope this review will inspire researchers working in various fields that deal with light, lighting design or manipulation of light to use the LSC to perform science that they may not have initially considered. Likewise, by stimulating researchers working on luminescent species, improved performance of the devices can be realized which could make them viable candidates for commercialization in many different areas.

\section{Acknowledgements}

M.P would like to thank the UK Engineering and Physical Sciences Research Council (EPSRC) for a Doctoral training award grant no: 1632762. I.P and M.P would like to acknowledge support from the H2020 European Research Council (ERC) starting grant IntelGlazing grant no: 679891.

Received: ((will be filled in by the editorial staff))

Revised: ((will be filled in by the editorial staff)) Published online: ((will be filled in by the editorial staff))

\section{Contributions}

All authors contributed equally to this work.

\section{References}

[1] W. H. Weber, J. Lambe, Appl. Opt. 1976, 15, 2299.

[2] W. G. J. H. M. van Sark, K. W. J. Barnham, L. H. Slooff, A. J. Chatten, A.

Büchtemann, A. Meyer, S. J. McCormack, R. Koole, D. J. Farrell, R. Bose, E. E.

Bende, A. R. Burgers, T. Budel, J. Quilitz, M. Kennedy, T. Meyer, C. D. M. Donegá, 
A. Meijerink, D. Vanmaekelbergh, Opt. Express 2008, 16, 21773.

[3] B. McKenna, R. C. Evans, Adv. Mater. 2017, 29, 1606491.

[4] M. Rafiee, S. Chandra, H. Ahmed, S. J. McCormack, Opt. Mater. (Amst). 2019, 91, 212.

[5] M. R. Kulish, Semicond. Phys. Quantum Electron. Optoelectron. 2016, 19, 229.

[6] B. V. G. Mohan, V. Vasu, V. Vasu, A. Robson Benjamin, M. Kottaisamy, Curr. Sci. 2018, 114, 1656.

[7] A. Alamoudi, S. M. Saaduddin, A. B. Munir, F. Muhammad-Sukki, S. H. Abu-Bakar, S. H. Mohd Yasin, R. Karim, N. A. Bani, A. Abubakar Mas'ud, J. A. Ardila-Rey, R. Prabhu, N. Sellami, Sustainability 2019, 11, 3056.

[8] P. Moraitis, R. E. I. Schropp, W. G. J. H. M. van Sark, Opt. Mater. (Amst). 2018, 84, 636.

[9] F. Meinardi, F. Bruni, S. Brovelli, Nat. Rev. Mater. 2017, 2, 17072.

[10] R. A. S. Ferreira, S. F. H. Correia, A. Monguzzi, X. Liu, F. Meinardi, Mater. Today 2020, 33, 105.

[11] J. Roncali, Adv. Energy Mater. 2020, 10, 2001907.

[12] R. Mazzaro, A. Vomiero, Adv. Energy Mater. 2018, 8, 1801903.

[13] M. Kanellis, M. M. de Jong, L. Slooff, M. G. Debije, Renew. Energy 2017, 103, 647.

[14] M. G. Debije, P. P. C. Verbunt, Adv. Energy Mater. 2012, 2, 12.

[15] Y. Kalisky, J. Lumin. 2018, 193, 10.

[16] L. H. Slooff, E. E. Bende, A. R. Burgers, T. Budel, M. Pravettoni, R. P. Kenny, E. D. Dunlop, A. Büchtemann, Phys. status solidi-Rapid Res. Lett. 2008, 2, 257.

[17] L. Desmet, A. J. M. Ras, D. K. G. de Boer, M. G. Debije, Opt. Lett. 2012, 37, 3087.

[18] Á. Bognár, S. Kusnadi, L. H. Slooff, C. Tzikas, R. C. G. M. Loonen, M. M. de Jong, J. L. M. Hensen, M. G. Debije, Renew. Energy 2020, 151, 1141. 
[19] W. van Sark, P. Moraitis, C. Aalberts, M. Drent, T. Grasso, Y. L'Ortije, M. Visschers, M. Westra, R. Plas, W. Planje, Sol. RRL 2017, 1, 1600015.

[20] A. Kerrouche, D. A. Hardy, D. Ross, B. S. Richards, Sol. Energy Mater. Sol. Cells 2014, 122, 99 .

[21] C. Corrado, S. W. Leow, M. Osborn, I. Carbone, K. Hellier, M. Short, G. Alers, S. A. Carter, J. Renew. Sustain. Energy 2016, 8, 043502.

[22] A. Reinders, M. G. Debije, A. Rosemann, IEEE J. Photovoltaics 2017, 7, 1663.

[23] A. Reinders, R. Kishore, L. Slooff, W. Eggink, Jpn. J. Appl. Phys. 2018, 57, 08RD10.

[24] P. Bernardoni, M. Tonezzer, D. Vincenzi, V. Guidi, S. Baricordi, G. Calabrese, in 31st EU PVSEC, 2015, pp. 2639-2641.

[25] Y. Zhao, G. A. Meek, B. G. Levine, R. R. Lunt, Adv. Opt. Mater. 2014, 2, 606.

[26] S. K. E. Hill, R. Connell, J. Held, C. Peterson, L. Francis, M. A. Hillmyer, V. E. Ferry, U. Kortshagen, ACS Appl. Mater. Interfaces 2020, 12, 4572.

[27] I. Papakonstantinou, C. Tummeltshammer, Optica 2015, 2, 841.

[28] G. Smestad, H. Ries, R. Winston, E. Yablonovitch, Sol. Energy Mater. 1990, 21, 99.

[29] E. Yablonovitch, J. Opt. Soc. Am. 1980, 70, 1362.

[30] S. Hemming, Acta Hortic. 2011, 25.

[31] S. Woei Leow, C. Corrado, M. Osborn, M. Isaacson, G. Alers, S. A. Carter, J. Appl. Phys. 2013, 113, DOI 10.1063/1.4807413.

[32] M. E. Loik, S. A. Carter, G. Alers, C. E. Wade, D. Shugar, C. Corrado, D. Jokerst, C. Kitayama, Earth's Futur. 2017, 5, 1044.

[33] C. Lamnatou, D. Chemisana, Renew. Sustain. Energy Rev. 2013, 18, 271.

[34] N. S. Makarov, K. Ramasamy, A. Jackson, A. Velarde, C. Castaneda, N. Archuleta, D. Hebert, M. R. Bergren, H. McDaniel, ACS Nano 2019, 13, 9112.

[35] M. Raeisossadati, N. R. Moheimani, D. Parlevliet, Renew. Sustain. Energy Rev. 2019, 
$101,47$.

[36] H. Videira, Novel Applications of Luminescence for Solar Energy, Imperial College London, 2016.

[37] L. Wondraczek, M. Batentschuk, M. A. Schmidt, R. Borchardt, S. Scheiner, B. Seemann, P. Schweizer, C. J. Brabec, Nat. Commun. 2013, 4, 2047.

[38] H. Delavari Amrei, B. Nasernejad, R. Ranjbar, S. Rastegar, J. Appl. Phycol. 2014, 26, 1493.

[39] A. M. Detweiler, C. E. Mioni, K. L. Hellier, J. J. Allen, S. A. Carter, B. M. Bebout, E. E. Fleming, C. Corrado, L. E. Prufert-Bebout, Algal Res. 2015, 9, 170.

[40] J.-M. Delgado-Sanchez, Sol. Energy Mater. Sol. Cells 2019, 202, 110134.

[41] L. H. Slooff, N. J. Bakker, P. M. Sommeling, A. Büchtemann, A. Wedel, W. G. J. H. M. Van Sark, Phys. Status Solidi Appl. Mater. Sci. 2014, 211, 1150.

[42] M. G. Debije, C. Tzikas, V. A. Rajkumar, M. M. de Jong, Renew. Energy 2017, 113, 1288.

[43] G. H. Timmermans, S. Hemming, E. Baeza, E. A. J. van Thoor, A. P. H. J. Schenning, M. G. Debije, Adv. Opt. Mater. 2020, 8, 2000738.

[44] A. A. Earp, J. B. Franklin, G. B. Smith, Sol. Energy Mater. Sol. Cells 2011, 95, 1157.

[45] A. A. Earp, G. B. Smith, J. Franklin, P. Swift, Sol. Energy Mater. Sol. Cells 2004, 84, 411.

[46] A. Zastrow, V. Wittwer, in SPIE (Eds.: C.-G. Granqvist, C.M. Lampert, J.J. Mason, V. Wittwer), 1986, p. 93.

[47] P. Swift, G. B. Smith, Appl. Opt. 2003, 42, 5112.

[48] J. Sathian, J. D. Breeze, B. Richards, N. M. Alford, M. Oxborrow, Opt. Express 2017, 25,13714

[49] M. G. Debije, V. A. Rajkumar, Sol. Energy 2015, 122, 334. 
[50] A. Renny, C. Yang, R. Anthony, R. R. Lunt, J. Chem. Educ. 2018, 95, 1161.

[51] J. ter Schiphorst, M. L. M. K. H. Y. K. Cheng, M. van der Heijden, R. L. Hageman, E.

L. Bugg, T. J. L. Wagenaar, M. G. Debije, Energy Build. 2020, 207, 109625.

[52] “https://lusoco.com/," n.d.

[53] G. Ciamician, Science (80-. ). 1912, 36, 385.

[54] M. Oelgemöller, Chem. Rev. 2016, 116, 9664.

[55] D. Cambié, F. Zhao, V. Hessel, M. G. Debije, T. Noël, Angew. Chemie Int. Ed. 2017, $56,1050$.

[56] G. X. de Oliveira, J. O. B. Lira, D. Cambié, T. Noël, H. G. Riella, N. Padoin, C. Soares, Chem. Eng. Res. Des. 2020, 153, 626.

[57] F. Zhao, Z. Chen, W. Fan, J. Dou, L. Li, X. Guo, Chem. Eng. J. 2020, 389, 124409.

[58] F. Zhao, D. Cambié, V. Hessel, M. G. Debije, T. Noël, Green Chem. 2018, 20, 2459.

[59] D. Cambié, J. Dobbelaar, P. Riente, J. Vanderspikken, C. Shen, P. H. Seeberger, K. Gilmore, M. G. Debije, T. Noël, Angew. Chemie Int. Ed. 2019, 58, 14374.

[60] F. Zhao, D. Cambié, J. Janse, E. W. Wieland, K. P. L. Kuijpers, V. Hessel, M. G. Debije, T. Noël, ACS Sustain. Chem. Eng. 2018, 6, 422.

[61] J. J. H. Videira, A. J. Cowan, A. J. Chatten, K. W. J. Barnham, A. Hankin, J. P. Connolly, M. Leak, J. Johnson, G. H. Kelsall, K. Kennedy, J. S. Roberts, in 2015 IEEE 42nd Photovolt. Spec. Conf., IEEE, 2015, pp. 1-6.

[62] G. Panzeri, E. Tatsi, G. Griffini, L. Magagnin, ACS Appl. Energy Mater. 2020, 3, 1665.

[63] J. Jia, L. C. Seitz, J. D. Benck, Y. Huo, Y. Chen, J. W. D. Ng, T. Bilir, J. S. Harris, T. F. Jaramillo, Nat. Commun. 2016, 7, 13237.

[64] K. R. McIntosh, N. Yamada, B. S. Richards, Appl. Phys. B 2007, 88, 285.

[65] S. F. H. Correia, P. P. Lima, P. S. André, M. R. S. Ferreira, L. A. D. Carlos, Sol. Energy Mater. Sol. Cells 2015, 138, 51. 
[66] R. H. Inman, G. V. Shcherbatyuk, D. Medvedko, A. Gopinathan, S. Ghosh, Opt. Express 2011, 19, 24308.

[67] K. Jakubowski, C.-S. Huang, A. Gooneie, L. F. Boesel, M. Heuberger, R. Hufenus, Mater. Des. 2020, 189, 108518.

[68] F. Mateen, H. Oh, J. Kang, S. Y. Lee, S.-K. Hong, Renew. Energy 2019, 138, 691.

[69] O. Y. Edelenbosch, M. Fisher, L. Patrignani, W. G. J. H. M. van Sark, A. J. Chatten, Opt. Express 2013, 21, A503.

[70] J. J. Videira, E. Bilotti, A. J. Chatten, in 2014 IEEE 40th Photovolt. Spec. Conf., IEEE, 2014, pp. 2280-2285.

[71] E.-H. Banaei, A. F. Abouraddy, Prog. Photovoltaics Res. Appl. 2015, 23, 403.

[72] I. Parola, M. A. Illarramendi, F. Jakobs, J. Kielhorn, D. Zaremba, H.-H. Johannes, J. Zubia, Polymers (Basel). 2019, 11, 1187.

[73] K. J. Lee, J. H. Oh, Y. Kim, J. Jang, Adv. Mater. 2006, 18, 2216.

[74] O. Besida, Y. Piret, F. Rondeaux, in AIP Conf. Proc., 2019, p. 050004.

[75] J.-Y. Chen, Y.-C. Chiu, C.-C. Shih, W.-C. Wu, W.-C. Chen, J. Mater. Chem. A 2015, 3,15039 .

[76] C. A. C. Chazot, S. Nagelberg, C. J. Rowlands, M. R. J. Scherer, I. Coropceanu, K. Broderick, Y. Kim, M. G. Bawendi, P. T. C. So, M. Kolle, Nat. Photonics 2020, 14, 310.

[77] A. Goetzberger, W. Greube, Appl. Phys. 1977, 14, 123.

[78] M. Gajic, F. Lisi, N. Kirkwood, T. A. Smith, P. Mulvaney, G. Rosengarten, Sol. Energy 2017, 150, 30.

[79] T. A. Geervliet, I. Gavrila, G. Iasilli, F. Picchioni, A. Pucci, Chem. - An Asian J. 2019, $14,877$.

[80] E. Tatsi, G. Fortunato, B. Rigatelli, G. Lyu, S. Turri, R. C. Evans, G. Griffini, ACS 
Appl. Energy Mater. 2020, 3, 1152.

[81] A. R. Frias, S. F. H. Correia, M. Martins, S. P. M. Ventura, E. Pecoraro, S. J. L.

Ribeiro, P. S. André, R. A. S. Ferreira, J. A. P. Coutinho, L. D. Carlos, Adv. Sustain. Syst. 2019, 1800134, 1800134.

[82] X. Liu, B. Luo, J. Liu, D. Jing, D. Benetti, F. Rosei, J. Mater. Chem. A 2020, 8, 1787.

[83] R. Kondepudi, S. Srinivasan, Sol. Energy Mater. 1990, 20, 257.

[84] M. Buffa, S. Carturan, M. G. Debije, A. Quaranta, G. Maggioni, Sol. Energy Mater. Sol. Cells 2012, 103, 114.

[85] I. A. Carbone, K. R. Frawley, M. K. McCann, Int. J. Photoenergy 2019, 2019, 1.

[86] C. Tummeltshammer, A. Taylor, A. J. Kenyon, I. Papakonstantinou, Opt. Lett. 2016, $41,713$.

[87] M. Portnoi, C. Sol, C. Tummeltshammer, I. Papakonstantinou, Opt. Lett. 2017, 42, 2695.

[88] M. Portnoi, T. J. Macdonald, C. Sol, T. S. Robbins, T. Li, J. Schläfer, S. Guldin, I. P. Parkin, I. Papakonstantinou, Nano Energy 2020, 70, 104507.

[89] M. . McMahon, J. . Kelly, Sci. Hortic. (Amsterdam). 1999, 79, 207.

[90] A. Goetzberger, Sol. Energy 1979, 22, 435.

[91] W. Stahl, V. Wittwer, A. Goetzberger, Sol. Energy 1986, 36, 27.

[92] V. Wittwer, W. Stahl, A. Goetzberger, Proc. SPIE 1983, 2, 80.

[93] M. J. Kastelijn, C. W. M. Bastiaansen, M. G. Debije, Opt. Mater. (Amst). 2009, 31, 1720.

[94] C.-S. Huang, K. Jakubowski, S. Ulrich, S. Yakunin, M. Clerc, C. Toncelli, R. M. Rossi, M. V. Kovalenko, L. F. Boesel, Nano Energy 2020, 76, 105039.

[95] V. A. Rajkumar, C. Weijers, M. G. Debije, Renew. Energy 2015, 80, 308.

[96] M. H. Sanders, R. J. Sedwick, J. Spacecr. Rockets 2019, 56, 1831. 
[97] S.-J. Ha, J.-H. Kang, D. H. Choi, S. K. Nam, E. Reichmanis, J. H. Moon, ACS Photonics 2018, 5, 3621.

[98] S. K. Nam, K. Kim, J.-H. Kang, J. H. Moon, Nanoscale 2020, 12, 17265.

[99] J. C. Goldschmidt, U. Aeberhard, R. Capek, Mi. G. Debije, W. Evers, S. Fischer, B. Fröhlich, M. Hermle, B. Herter, A. Ivaturi, K. W. Krämer, E. Lifshitz, R. MartínRodríguez, S. K. W. MacDougall, A. Meijerink, E. A. Moulin, T. C. M. Müller, U. Paetzold, B. S. Richards, S. Wolf, M. Warzecha, C. Wouters, Y. Zhao, in Renew. Energy Environ., OSA, Washington, D.C., 2013, p. PT3C.2.

[100] S. Latreche, M. Fathi, A. Kadri, Chinese Phys. B 2019, 28, 088801.

[101] G. Macia-Fernandez, P. Garcia-Teodoro, J. Diaz-Verdejo, IEEE Wirel. Commun. 2009, 16,88 .

[102] M. Portnoi, P. A. Haigh, T. J. Macdonald, F. Ambroz, I. P. Parkin, I. Darwazeh, I. Papakonstantinou, Bandwidth Limits of Luminescent Solar Concentrators as Detectors in Free-Space Optical Communication Systems, Light: Science \& Applications (Accepted, In Press), 2020.

[103] L. Protesescu, S. Yakunin, M. I. Bodnarchuk, F. Krieg, R. Caputo, C. H. Hendon, R. X. Yang, A. Walsh, M. V. Kovalenko, Nano Lett. 2015, 15, 3692.

[104] M. Savarese, A. Aliberti, I. De Santo, E. Battista, F. Causa, P. A. Netti, N. Rega, J. Phys. Chem. A 2012, 116, 7491.

[105] S. Collins, D. C. O’Brien, A. Watt, Opt. Lett. 2014, 39, 1756.

[106] Y. Shen, Y. Jia, X. Sheng, L. Shen, J. A. Rogers, N. C. Giebink, ACS Photonics 2014, $1,746$.

[107] P. P. Manousiadis, S. Rajbhandari, R. Mulyawan, D. A. Vithanage, H. Chun, G. Faulkner, D. C. O’Brien, G. A. Turnbull, S. Collins, I. D. W. Samuel, Optica 2016, 3, 702. 
[108] Y. Dong, M. Shi, X. Yang, P. Zeng, J. Gong, S. Zheng, M. Zhang, R. Liang, Q. Ou, N. Chi, S. Zhang, Opt. Express 2017, 25, 21926.

[109] T. Peyronel, K. J. Quirk, S. C. Wang, T. G. Tiecke, Optica 2016, 3, 787.

[110] P. P. Manousiadis, H. Chun, S. Rajbhandari, D. A. Vithanage, R. Mulyawan, G. Faulkner, H. Haas, D. C. O’Brien, S. Collins, G. A. Turnbull, I. D. W. Samuel, $A d v$. Opt. Mater. 2020, 8, 1901139.

[111] A. R. Bastos, G. Lyu, T. Silvério, P. S. André, R. C. Evans, R. A. S. Ferreira, Cell Reports Phys. Sci. 2020, 1, 100041.

[112] A. Xie, C. Hettiarachchi, F. Maddalena, M. E. Witkowski, M. Makowski, W. Drozdowski, A. Arramel, A. T. S. Wee, S. V. Springham, P. Q. Vuong, H. J. Kim, C. Dujardin, P. Coquet, M. D. Birowosuto, C. Dang, Commun. Mater. 2020, 1, 37.

[113] X. Li, C. Meng, B. Huang, D. Yang, X. Xu, H. Zeng, Adv. Opt. Mater. 2020, 8, 2000273.

[114] M. Gandini, I. Villa, M. Beretta, C. Gotti, M. Imran, F. Carulli, E. Fantuzzi, M. Sassi, M. Zaffalon, C. Brofferio, L. Manna, L. Beverina, A. Vedda, M. Fasoli, L. Gironi, S. Brovelli, Nat. Nanotechnol. 2020, 15, 462.

[115] A. Koppelhuber, P. Wintersberger, C. Birklbauer, O. Bimber, in ACM SIGGRAPH 2014 Emerg. Technol. - SIGGRAPH '14, ACM Press, New York, New York, USA, 2014, pp. 1-1.

[116] A. Koppelhuber, S. Fanello, C. Birklbauer, D. Schedl, S. Izadi, O. Bimber, Opt. Express 2014, 22, 29531.

[117] A. Koppelhuber, O. Bimber, Opt. Express 2015, 23, 33713.

[118] A. Koppelhuber, C. Birklbauer, S. Izadi, O. Bimber, Opt. Express 2014, 22, 8928.

[119] I. Kurmi, D. C. Schedl, O. Bimber, Opt. Express 2018, 26, 29253.

[120] A. Koppelhuber, O. Bimber, Opt. Express 2015, 23, 33713. 
[121] I. S. Melnik, A. H. Rawicz, Appl. Opt. 1997, 36, 9025.

[122] R. Koeppe, A. Neulinger, P. Bartu, S. Bauer, Opt. Express 2010, 18, 2209.

[123] P. Bartu, R. Koeppe, N. Arnold, A. Neulinger, L. Fallon, S. Bauer, J. Appl. Phys. 2010, $107,123101$.

[124] Y. Tsutsumi, R. Matsumura, M. Ohta, I. Fujieda, Opt. Eng. 2019, 58, 1.

[125] C. Hirose, N. Fukuda, T. Sassa, K. Ishibashi, T. Ochiai, R. Furukawa, Fibers 2019, 7, DOI 10.3390/FIB7050037.

[126] K. Uzawa, T. Tozaki, K. Yano, E. Nihei, R. Furukawa, Jpn. J. Appl. Phys. 2020, 59, SDDF06.

[127] S. Kalathimekkad, J. Missinne, D. Schaubroeck, R. Mandamparambil, G. Van Steenberge, IEEE Sens. J. 2015, 15, 76.

[128] Y. Zhao, R. R. Lunt, Adv. Energy Mater. 2013, 3, 1143.

[129] M. G. Debije, Adv. Funct. Mater. 2010, 20, 1498.

[130] J. A. H. P. Sol, G. H. Timmermans, A. J. van Breugel, A. P. H. J. Schenning, M. G. Debije, Adv. Energy Mater. 2018, 8, 1702922.

[131] J. A. H. P. Sol, V. Dehm, R. Hecht, F. Würthner, A. P. H. J. Schenning, M. G. Debije, Angew. Chemie Int. Ed. 2018, 57, 1030.

[132] G. H. Timmermans, B. W. H. Saes, M. G. Debije, Appl. Opt. 2019, 58, 9823.

[133] F. Mateen, H. Oh, W. Jung, S. Y. Lee, H. Kikuchi, S. K. Hong, Liq. Cryst. 2018, 45, 498.

[134] P. P. C. Verbunt, D. K. G. de Boer, D. J. Broer, M. G. Debije, in 2015 IEEE 42nd Photovolt. Spec. Conf., IEEE, 2015, pp. 1-6. 


\section{T.O.C. Entry}

Luminescent Solar Concentrators are typically seen as flat, planar devices for concentrating sunlight, however, the devices have recently been employed in a much broader range of configurations and applications. This review explores the versatile and innovative methods in which these devices have been employed, reaching industries including agriculture, sensing, imaging and communications.

I. Papakonstantinou, M. Portnoi, and M. G. Debije

The Hidden Potential of Luminescent Solar Concentrators

ToC figure

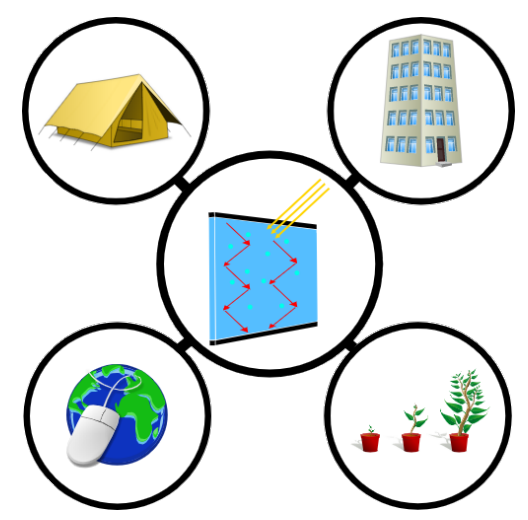

